\title{
QUALIDADE FISIOLÓGICA DA SEMENTE E DESEMPENHO DE PLANTAS ISOLADAS EM SOJA ${ }^{1}$
}

\author{
LUIS OSMAR BRAGA SCHUCH²; ELIANE MARIA KOLCHINSKI'; JONAS ALEX FINATTO4
}

\begin{abstract}
RESUMO - O presente trabalho teve como objetivo avaliar o efeito da qualidade fisiológica de sementes no rendimento de grãos em plantas isoladas de soja. O trabalho foi desenvolvido na Faculdade de Agronomia Eliseu Maciel (FAEM/UFPel) utilizando a cultivar de soja Mercedez. Os tratamentos constaram de dois níveis de qualidade fisiológica, alta e baixa. O delineamento experimental foi de blocos ao acaso com 11 repetições. Os níveis de qualidade fisiológica foram obtidos a partir de um lote de sementes com $90 \%$ de germinação e $69 \%$ de vigor, utilizando como critério o período de emergência, sendo que as plântulas emergidas até o $6^{\circ}$ dia após a semeadura foram consideradas provenientes de sementes de alta qualidade fisiológica e até o $9^{\circ}$ e $10^{\circ}$ dias, de baixa qualidade. $\mathrm{Na}$ implantação do experimento a campo semeou-se 06 sementes por cova e após emergência, realizouse o desbaste mantendo uma planta por cova de acordo com o tratamento (alta ou baixa qualidade fisiológica). Para avaliar o efeito da qualidade fisiológica sobre o desenvolvimento individual e evitar a competição entre plantas utilizou-se espaçamento de 0,50m nas entrelinhas e entre plantas na linha. O número de ramificações por planta e o peso de 1000 sementes, não foram afetados pelo nível de qualidade fisiológica das sementes. As plantas oriundas de sementes de alta qualidade fisiológica apresentam maior altura de plantas, diâmetro de caule e rendimento de grãos $25 \%$ superior.
\end{abstract}

Termos para indexação: soja, qualidade fisiológica, produtividade.

\section{SEED PHYSIOLOGICAL QUALITY AND INDIVIDUAL PLANTS PERFORMANCE IN SOYBEAN}

\begin{abstract}
The objective of this research was to evaluate the effect of seed physiological quality on the grain yield in isolated soybean plants. The experiment was conducted at the "Eliseu Maciel" Agriculture College (FAEM/UFPel) using the Mercedez soybean cultivars. This study evaluated two levels of seed physiological quality, high and low. A randomized complete block experimental design was used with eleven replications. The physiological quality levels were obtained from seed lots with $90 \%$ germination and $69 \%$ vigor, using the emergency period test as crition and the seedlings emerged up to the 6th day after sowing were considered as derived from seeds with high physiological quality and 9 and 10 th days from low quality seeds. In the experiment six seeds were sown per hill plot and after emergence they were thinned to one plant per hill plot based on treatment (high or low physiological quality). In order to evaluate the effect of physiological quality on individual plant development and to prevent competition between plants, $0.50 \mathrm{~m}$ spacing was used between the rows and between plants in the row. The number of ramifications/plants and the weight of a thousand seeds were not affected by the seed physiological quality. The plants from seeds with high physiological
\end{abstract}

${ }^{1}$ Submetido em 22/04/2008. Aceito para publicação em 18/10/2008.

${ }^{2}$ Eng. Agr., Dr., Professor Associado da Faculdade de Agronomia Eliseu Maciel da Universidade Federal de Pelotas (FAEM/UFPel), Bolsista do CNPq. Caixa Postal: 345, CEP: 96001-970. lobs@ufpel.edu.br.
${ }^{3}$ Eng. Agr., Dra., Professora Adjunta da Universidade Estadual do Rio Grande do Sul (UERGS). Encantado-RS. eliane-kolchinski@uergs.edu.br.

${ }^{4}$ Bolsista de Iniciação Científica da FAPERGS, Acadêmico da FAEM/ UFPel. 
quality showed greater plant height, stem diameter and grain yield 25\% higher than the seeds with low physiological quality.

Index terms: soybean, seed physiological, yield.

\section{INTRODUÇÃO}

A avaliação e descrição dos efeitos da qualidade fisiológica das sementes sobre o estabelecimento e desempenho das plantas de soja em condições de campo têm sido extremamente relevantes, devido à importância desta no agro-negócio e na economia nacional. O Brasil é um dos maiores produtores e exportadores de soja no mundo. Na safra 2006/07, o Brasil produziu 53,4 milhões de toneladas, em uma área de 22,2 milhões de hectares (Conab, 2008).

A qualidade fisiológica pode ser definida como a capacidade de desempenhar funções vitais, caracterizada pela germinação, vigor e longevidade, que afeta diretamente a implantação da cultura em condições de campo (Popinigis, 1977). Resultados de pesquisa mostram que a baixa qualidade fisiológica de sementes pode resultar em reduções na velocidade e emergência total, desuniformidade de emergência, menor tamanho inicial de plântulas, produção de matéria seca e na área foliar (Khah et al., 1989; Schuch, 1999; Höfs et al., 2004a; Kolchinski et al., 2006). Pintus e Kimel (1979) constataram que plântulas de soja provenientes de sementes com menor qualidade fisiológica emergiram posteriormentee apresentaram as primeiras folhas trifolioladas menores em relação às plântulas provenientes das sementes com alta qualidade, resultando em menor taxa de acúmulo de matéria seca durante o período de crescimento.

Schuch et al. (2000a) avaliando o comportamento de plantas isoladas de aveia, observou que as diferenças na produção de matéria seca entre os níveis de vigor foram gradativamente aumentando com o avanço no crescimento das plantas, e atribuiu ao desempenho inicial das plantas. Supõe-se que o maior tamanho inicial das plântulas pode proporcionar a maximização da exploração do ambiente, favorecendo o seu desenvolvimento. Segundo Merotto Júnior (1999), as plantas de emergência atrasada podem apresentar menor crescimento da parte aérea e do sistema radicular, e assim, menor capacidade de competição por água, luz e nutrientes.

O efeito do crescimento e desenvolvimento das plantas em função da qualidade fisiológica de sementes na produção final tem sido objeto de discussão. TeKrony et al. (1989) comentam que o vigor das sementes pode afetar o crescimento inicial das culturas, mas o efeito tende a reduzir com a evolução do crescimento, desaparecendo na maturação, o que foi constatado por Schuch et al. (2000b) em aveia-preta. Segundo Khah et al (1989), as vantagens iniciais das plantas originadas de sementes de alta qualidade tenderiam a diminuir com avanço no período de crescimento, em função da intensificação da competição entre plantas dentro das populações por recursos de crescimento (água, nutrientes e especialmente sombreamento mútuo), que inicia mais cedo em cultivos derivados de sementes de melhor qualidade, sob condições agrícolas normais. Segundo Marcos Filho (1999a), o vigor de sementes tem efeito direto na habilidade da planta acumular matéria seca, mas à medida que os estádios se sucedem, essa influência tende a reduzir e o desempenho da planta torna-se mais dependente das relações genótipo e ambiente. Segundo o autor, para as plantas produtoras de grãos, não é esperada influência da qualidade fisiológica das sementes sobre a produção final, quando não há redução significativa no estande inicial. No entanto, Tekrony e Egli, (1991) afirmam que o potencial fisiológico das sementes pode afetar indiretamente a produção da lavoura ao afetar a velocidade e a percentagem de emergência das plântulas e o estande inicial, bem como pode afetar diretamente o rendimento de grãos, através de sua influência no vigor nas plantas resultantes. Trabalhos têm mostrado que comunidades de plantas formadas a partir de sementes com melhor qualidade fisiológica apresentam rendimentos de grãos superiores, tais como em arroz irrigado (Höfs et al., 2004b; Melo et al., 2006a; Melo et al., 2006b) em arroz híbrido (Mielezrski, 2008) e em soja (Kolchinski et al., 2005; Scheeren, 2002). Kolchinski et al. (2005) trabalhando com comunidades constituídas de combinações de sementes com diferentes níveis de qualidade observaram que as plantas provenientes das sementes de alta qualidade apresentaram rendimento de grãos superiores. Constataram também que o aumento na proporção das sementes com alta qualidade no estabelecimento das comunidades de plantas de soja, proporcionou aumentos lineares no rendimento de sementes. Esses efeitos são devidos provavelmente à obtenção de plântulas com maior tamanho na emergência, 
o que proporcionou maiores taxas de crescimento inicial (Kolchinski, 2003; Schuch et al., 2000a; Machado e Schuch, 2004; Höfs, 2003) tendo essas diferenças refletido no rendimento de grãos. Nesse sentido, Scheeren (2002) observou que as plantas de soja provenientes das sementes de alta qualidade fisiológica apresentaram maior altura aos 21 dias após a semeadura, e aquela vantagem inicial, foi suficiente para resultar em maior rendimento de grãos.

Neste contexto, o presente trabalho teve como objetivo avaliar o efeito da qualidade fisiológica de sementes no comportamento de plantas isoladas de soja, incluindo o rendimento de grãos.

\section{MATERIAL E MÉTODOS}

O trabalho foi desenvolvido no Laboratório de Análise de Sementes e no Campo Didático e Experimental do Departamento de Fitotecnia da Faculdade de Agronomia “Eliseu Maciel” da Universidade Federal de Pelotas (FAEM/ UFPel), no município de Capão do Leão/RS.

Os tratamentos constaram de dois níveis de qualidade fisiológica, alta e baixa utilizando o cultivar de soja Mercedez. O delineamento experimental adotado foi de blocos ao acaso com 11 repetições.

A análise da germinação das sementes foi realizada conforme descrito por Brasil (1992), com 08 repetições de 50 sementes. O teste de envelhecimento acelerado para determinação do vigor foi realizado segundo metodologia descrita por Marcos Filho (1999b), utilizando 04 repetições de 50 sementes com 13\% de teor de água. As sementes foram colocadas sobre bandeja de tela de alumínio, fixada no interior de uma caixa plástica, funcionando como compartimento individual (mini-câmara) e com $40 \mathrm{~mL}$ de água destilada. As caixas foram mantidas em incubadora a temperatura de $42^{\circ} \mathrm{C}$, por um período de 72 horas. Posteriormente, foram submetidas ao teste de germinação e avaliadas segundo Brasil (1992).

O lote de sementes utilizado no experimento apresentou $90 \%$ de germinação e $69 \%$ de índice de vigor. Os níveis de qualidade fisiológica avaliados foram obtidos utilizando como critério o período de emergência, sendo que as plântulas emergidas até o $6^{\circ}$ dia após a semeadura foram consideradas provenientes de sementes de alta qualidade fisiológica e as emergidas no $9^{\circ}$ e $10^{\circ}$ dias de baixa qualidade. Na implantação do experimento semeou-se 06 sementes por cova e posteriormente, realizou-se o desbaste mantendo uma planta por cova de acordo com o tratamento (alta ou baixa qualidade fisiológica).
A avaliação do efeito da qualidade fisiológica sobre o desenvolvimento foi realizada em plantas isoladas. Com objetivo de evitar a competição entre as plantas utilizou-se espaçamento de $0,50 \mathrm{~m}$ nas entrelinhas e entre plantas na linha.

As semeaduras foram realizadas manualmente em 23/11/2005 em canteiros de 1,0m de largura por 5,5m de comprimento. A adubação e calagem foram realizadas a lanço e incorporadas no momento do preparo do solo. As doses foram determinadas segundo análise do solo e recomendação da Sociedade Brasileira de Ciência do Solo (2004). O controle de invasoras foi realizado manualmente. Não ocorreram infestações significativas de pragas e doenças.

Em cada parcela foram realizadas as seguintes determinações: número de ramificações por planta, altura das plantas, diâmetro do caule, número de grãos por planta, rendimento de grãos e os componentes de rendimento, número de vagens por planta, número de sementes por vagens e peso de mil sementes.

A altura de plantas e diâmetro do caule e foram determinados por ocasião da colheita. O diâmetro foi medido ao nível do solo com o uso de paquímetro e a altura com auxílio de régua graduada. O peso de mil sementes foi determinado pela pesagem das sementes produzidas em cada planta, corrigido para peso de 1000 sementes.

O rendimento de sementes foi determinado pela pesagem das sementes produzidas em cada planta, corrigido para o teor de água de $13 \%$.

Os resultados foram avaliados através da análise de variância e as médias comparadas pelo teste de Duncan no nível de 5\% de probabilidade.

\section{RESULTADOS E DISCUSSÃO}

Os resultados apresentados na tabela 1 mostram que não ocorreu diferença significativa no número de ramificações entre os níveis de qualidade fisiológica. Por outro lado, as sementes de alta qualidade fisiológica produziram plantas com maior altura e diâmetro de caule. Efeitos da qualidade fisiológica das sementes sobre a altura também foram constatados em outros trabalhos, no entanto, em avaliações realizadas em períodos diferentes do desenvolvimento das plantas. Em aveia, Machado (2002) avaliou o comportamento das plantas até os 30 dias após a emergência e constatou que as plantas oriundas das sementes de alta qualidade apresentaram maior altura durante todo o período. Vanzolini e Carvalho (2002) observaram que lotes de sementes de soja com baixa qualidade fisiológica resultaram em plantas 
com menores alturas aos 18 e 38 DAS em comparação aos lotes de média e alta qualidade. Segundo os autores, estes dados provavelmente, refletem a velocidade de emergência das plântulas originadas de sementes de baixa qualidade fisiológica, significativamente menor em relação aos demais lotes. Kolchinski et al. (2006) observaram que plantas de soja originadas de sementes de maior qualidade fisiológica apresentaram maiores taxas de crescimento da cultura resultando em plantas com maior massa seca e área foliar aos 30 dias após a emergência, sendo que resultados semelhantes foram observados por Machado e Schuch (2004), Höfs et al. (2004a) e Schuch et al. (2000b).

TABELA 1. Número de ramificações por planta, altura de plantas e diâmetro de caule em plantas de soja em função da qualidade fisiológica das sementes, Capão do Leão, RS, 2005/06.

\begin{tabular}{cccc}
\hline $\begin{array}{c}\text { Qualidade } \\
\text { Fisiológica }\end{array}$ & $\begin{array}{c}\text { Número de } \\
\text { ramificações }\end{array}$ & $\begin{array}{c}\text { Altura } \\
(\mathrm{cm})\end{array}$ & $\begin{array}{c}\text { Diâmetro do } \\
\text { Caule }(\mathrm{mm})\end{array}$ \\
\hline Alta & $9.8 \mathrm{a}$ & $71 \mathrm{a}$ & $17.6 \mathrm{a}$ \\
Baixa & $9.5 \mathrm{a}$ & $64 \mathrm{~b}$ & $15.4 \mathrm{~b}$ \\
Média & 9.6 & 68 & 16.5 \\
\hline CV $(\%)$ & 2.67 & 7.12 & 9.38 \\
\hline
\end{tabular}

As médias dentro de cada coluna seguidas da mesma letra não diferem entre si pelo teste de Duncan, em 5\% de probabilidade.

Os dados apresentados na tabela 2 mostram que as plantas provenientes de sementes com alta qualidade fisiológica apresentaram maior rendimento de grãos. Efeitos da qualidade fisiológica das sementes no rendimento de grãos em soja também foram observados por Popinigis (1973), Pintus e Kimel (1979), Scheeren (2002) e Kolchinski et al. (2005).
Popinigis (1973) constatou que as sementes de soja com alta qualidade fisiológica produziram plantas com maior número de racemos e de vagens resultando em maior rendimento de sementes. Kolchinski et al. (2005) avaliando o comportamento individual de plantas em comunidades de soja constatou que o efeito da qualidade fisiológica das sementes sobre o crescimento inicial das plantas determinou maiores rendimentos de sementes. Segundo os autores, o uso de sementes com alta qualidade fisiológica proporcionou maiores área foliar e produção de matéria seca e consequentemente vantagem competitiva inicial no aproveitamento dos recursos do ambiente, o que refletiu nos estádios posteriores de desenvolvimento até a fase de maturação resultando em maior rendimento de sementes. Scheeren (2002) observou que as plantas provenientes das sementes de soja de alta qualidade fisiológica apresentaram maiores altura inicial e rendimento de grãos.

Comparando os resultados obtidos no experimento (tabela 2), o rendimento obtido em plantas isoladas de soja quando se utilizou sementes de alta qualidade foi de aproximadamente, $25 \%$ superior em relação às de baixa qualidade. Kolchinski et al. (2005) avaliando o comportamento de plantas provenientes de alta e baixa qualidade fisiológica em comunidades de plantas de soja observaram rendimento $35 \%$ superior com a utilização de sementes de alta qualidade. Também em soja, Popinigis (1973) obteve rendimento de 16\% superior em plantas oriundas de semente de alta qualidade fisiológica em comparação com as de baixa.

O maior rendimento foi determinado pelo componente número de vagens por planta, já que os demais não apresentaram diferença significativa entre os níveis de qualidade fisiológica. Popinigis (1973), Pintus e Kimel (1979) e Kolchinski et al. (2005) também constataram que o maior rendimento em plantas provenientes de sementes de alta qualidade fisiológica foi devido ao aumento do número de vagens por planta.

TABELA 2. Rendimento de grãos e componentes de rendimento em plantas de soja em função da qualidade fisiológica das sementes, Capão do Leão, RS, 2005/06.

\begin{tabular}{cccccc}
\hline $\begin{array}{c}\text { Qualidade } \\
\text { Fisiológica }\end{array}$ & $\begin{array}{c}\text { Rendimento de } \\
\text { grãos por planta (g) }\end{array}$ & $\begin{array}{c}\text { Número de legumes } \\
\text { por planta }\end{array}$ & $\begin{array}{c}\text { Número de grãos } \\
\text { por legume }\end{array}$ & $\begin{array}{c}\text { Peso de Mil } \\
\text { sementes (g) }\end{array}$ & $\begin{array}{c}\text { Número de grãos } \\
\text { por planta }\end{array}$ \\
\hline Alta & $73.0 \mathrm{a}$ & $282 \mathrm{a}$ & $1.76 \mathrm{a}$ & $148 \mathrm{a}$ & $495 \mathrm{a}$ \\
Baixa & $58.6 \mathrm{~b}$ & $232 \mathrm{~b}$ & $1.78 \mathrm{a}$ & $140 \mathrm{a}$ & $412 \mathrm{~b}$ \\
Média & 65.8 & 257 & 1.76 & 140 & 454 \\
\hline CV $(\%)$ & 15.54 & 13.75 & 6.15 & 3.93 & 11.58 \\
\hline
\end{tabular}

As médias dentro de cada coluna seguidas da mesma letra não diferem entre si pelo teste de Duncan, em 5\% de probabilidade. 
Devido ao efeito da qualidade fisiológica das sementes sobre o número de vagens por plantas, o número de grãos por planta também foi significativamente superior.

\section{CONCLUSÕES}

Plantas oriundas de sementes de alta e baixa qualidade fisiológica não diferem no número de ramificações por planta e no peso de 1000 sementes.

As plantas oriundas de sementes de alta qualidade fisiológica apresentam maior altura, diâmetro de caule e rendimento de grãos $25 \%$ superior às obtidas de sementes de baixa qualidade.

\section{REFERÊNCIAS}

BRASIL. Ministério da Agricultura e da Reforma Agrária. Regras para análise de sementes. Brasília, DF: SNDA/ DNPV/CLAV, 1992. 365p.

CONAB. Safras: comparativo da área, produção e produtividade. Disponível em : <http://www.conab.gov.br $>$. Acesso em fev. 2008.

HÖFS, A. Vigor de sementes de arroz e desempenho da cultura. 2003. 44f. Tese (Doutorado em Fitotecnia) Faculdade de Agronomia "Eliseu Maciel” da Universidade Federal de Pelotas, Peloras.

HÖFS, A.; SCHUCH, L.O.B.; PESKE, S.T.; BARROS, A.C.S.A. Emergência e crescimento de plântulas de arroz em resposta à qualidade fisiológica de sementes. Revista Brasileira de Sementes, v.26, n.1, p.92-97, 2004a.

HÖFS, A.; SCHUCH, L.O.B.; PESKE, S.T.; BARROS, A.C.S.A. Efeito da qualidade fisiológica das sementes e da densidade de semeadura sobre o rendimento de grãos e qualidade industrial em arroz. Revista Brasileira de Sementes, v.26, n.2, p.55-62, 2004b.

KHAH, E. M.; ROBERTS, E. H.; ELLIS, R. H. Effects of seed ageing on growth and yield of spring wheat at different plant-population densities. Field Crops Research, v.20, p.175-190, 1989.

KOLCHINSKI, E. M. Vigor de sementes de soja e aspectos do desempenho em campo. 2003. 44f. Tese (Doutorado em Fitotecnia) - Faculdade de Agronomia "Eliseu Maciel" da Universidade Federal de Pelotas, Pelotas.

KOLCHINSKI, E. M.; SCHUCH, L. O. B.; PESKE, S. T. Vigor de sementes e competição intra-específica em soja. Ciência Rural, v.35, n.6, p.1248-1256, 2005.
KOLCHINSKI, E. M. ; SCHUCH, L. O. B. ; PESKE, S. T. . Crescimento inicial de soja em função do vigor de sementes. Revista Brasileira de Agrociência, v. 12, p. 163-166, 2006.

MACHADO, R. F. Desempenho de aveia-preta (Avena sativa L.) em função do vigor de sementes e população de plantas. 2002. 46f. Dissertação (Mestrado em Fitotecnia) Faculdade de Agronomia "Eliseu Maciel” da Universidade Federal de Pelotas, Pelotas.

MACHADO, R.F.; SCHUCH, L.O.B. Produção de forragem e de sementes de aveia branca em função do vigor de sementes e populações de plantas. Revista Científica Rural, v.9, n.1, p.126-136, 2004.

MARCOS FILHO, J. Conceitos e testes de vigor para sementes de soja. In: CONGRESSO BRASILEIRO DE SOJA, Londrina. Anais... Londrina: Embrapa Soja, 1999. p.220-226.a

MARCOS FILHO, J. Testes de envelhecimento acelerado. In: KRZYZANOWSKI, F.C.; VIEIRA, R.D.; FRANÇA NETO, J. de B. Vigor de sementes: conceitos e testes. Londrina: ABRATES, 1999. Cap.3, p.1-24.b

MELO, P.T.B.S.; SCHUCH, L.O.B.; ASSIS, F.N.; CONCENÇO, G. Comportamento de populações de arroz irrigado em função das proporções de plantas originadas de sementes de alta e baixa qualidade fisiológica. Revista Brasileira de Agrociência, v.12, n.1, p.37-43, 2006a.

MELO, P.T.B.S.; SCHUCH, L.O.B.; ASSIS, F.N.; CONCENÇO, G. Comportamento individual de plantas originadas de sementes com diferentes níveis de qualidade fisiológica em populações de arroz irrigado. Revista Brasileira de Sementes, v.28, n.2, p.84-94, 2006b.

MIELEZRSKI, F. Comportamento de plantas de arroz híbrido em função da qualidade fisiológica das sementes. 2008. 46f. Dissertação (Mestrado em Fitotecnia) - Faculdade de Agronomia "Eliseu Maciel" da Universidade Federal de Pelotas, Pelotas.

MEROTTO JÚNIOR, A. et al. A desuniformidade de emergência reduz o rendimento de grãos de milho. Ciência Rural, v.29, n.4, p.595-601, 1999.

PINTHUS, M.J.; KIMEL, U. Speed of germination as criterion of seed vigor in soybeans. Crop Science, v.19, p.291-292, 1979. Popinigis, 1979.

POPINIGIS, F. Fisiologia da semente. Brasília, DF: AGIPLAN, 1977.

POPINIGIS, F. Effects of the physiological quality of seed on field performance of soybeans (Glycine max $(L$. 
Merrill) as affected by population density. 1973. $87 \mathrm{f}$. Thesis. (PhD in Agronomy) - Mississippi State University.

SCHEEREN, B.R. Vigor das sementes de soja e produtividade. 2002. 48f. Tese (Doutorado) - Faculdade de Agronomia "Eliseu Maciel” da Universidade Federal de Pelotas, Pelotas.

SCHUCH, L. O. B. Vigor das sementes e aspectos da fisiologia da produção em aveia-preta (Avena strigosa Schreb.). 1999. 127f. Tese (Doutorado em Fitotecnia). Faculdade de Agronomia "Eliseu Maciel” da Universidade Federal de Pelotas, Pelotas

SCHUCH, L. O. B.; NEDEL, J. L.; ASSIS, F. N.; MAIA, M.S. Emergência em campo e crescimento inicial de aveia preta em resposta ao vigor das sementes. Revista Brasileira de Agrociência, v.6, n.2, p. 97-101, 2000a.

SCHUCH, L. O. B.; NEDEL, J. L.; ASSIS, F. N. Vigor de sementes e análise de crescimento de aveia preta. Scientia Agricola, v.57, n.2, p.305-312, 2000b.

SOCIEDADE BRASILEIRA DE CIÊNCIA DO SOLO. Comissão de Química e Fertilidade do Solo. Manual de adubação e calagem: para os estados do Rio Grande do Sul e de Santa Catarina. 10.ed. Porto Alegre: SBCS - Núcleo Regional Sul, 2004. 394p.

TeKRONY, D.M.; EGLI, D. B. Relationship of seed vigor to crop yield: a review. Crop Science, v.31, p.816-822, 1991.

TeKRONY, D.M.; EGLI, D.B.; WICKHAM, D.A. Corn seed vigor on no-tillage field performance. II. Plant growth and grain yield. Crop Science, v.29, p.1528-1531, 1989.

VANZOLINI, S.; CARVALHO, N. M. Efeito do vigor de sementes de soja sobre o seu desempenho em campo. Revista Brasileira de Sementes, v.24, n.1, p.33-41, 2002. 